\title{
Using Intuitionistic Fuzzy TOPSIS in Site Selection of Wind Power Plants in Turkey
}

\author{
Babak Daneshvar Rouyendegh (B. Erdebilli) (D), \\ Abdullah Yildizbasi $(\mathbb{D}$, and Ümmühan Z. B. Arikan \\ Department of Industrial Engineering, Ankara Yıldırım Beyazıt University (AYBU), 06010 Ankara, Turkey \\ Correspondence should be addressed to Babak Daneshvar Rouyendegh (B. Erdebilli); babek.erdebilli2015@gmail.com
}

Received 31 May 2018; Accepted 1 August 2018; Published 16 August 2018

Academic Editor: Jiefeng Liu

Copyright (C) 2018 Babak Daneshvar Rouyendegh (B. Erdebilli) et al. This is an open access article distributed under the Creative Commons Attribution License, which permits unrestricted use, distribution, and reproduction in any medium, provided the original work is properly cited.

\begin{abstract}
The reduction of energy resources and the increase in environmental consciousness have recently increased the interest in renewable energy sources. Wind energy is from renewable energy sources, which are used in many countries. Turkey has a lot alternative wind energy plants thanks to its favorable geographical location. Where the wind power plant is to be established is a complex and important decisive factor. It is very important to select the appropriate wind power plant site to take advantage of wind energy and reduce costs. In this study, we aimed to reach the solution of wind energy plant site selection. For this purpose 4 alternative wind power plant locations have been identified. To evaluate the alternatives, 10 criteria in four dimensions including wind potential, location, cost, and social benefits are selected. Since the Multicriterion Decision Making (MCDM) methods are often used in problem of location selection from past to present, TOPSIS method combined with intuitionistic fuzzy set (IFS) has been used to achieve this goal. The main purpose of the TOPSIS method is to rank the alternatives in the worst way. The IFS are used to reflect approval, rejection, and hesitation of decision makers by dealing with real life uncertainty, imprecision, vagueness, and linguistic human decisions. Finally, a numerical example is applied for wind power plant site selection. In order to demonstrate the effectiveness of IFS, the problem is solved by the Fuzzy TOPSIS method using the same data. Then, the obtained results are compared with the IFS method to show the effectiveness of the proposed method.
\end{abstract}

\section{Introduction}

Increased living standards have also increased the need for energy. The shortage of fossil fuels and the negative effects on the environment have created a need for clean energy [1]. Radioactive waste generated by nuclear power plants and security problems, especially the explosion of nuclear power plants in Japan Fukushima, triggered the tendency for renewable energy sources [2].

The use of renewable energy sources ensures sustainable development. Reducing the use of fossil fuels and energy imports, achieving national targets by increasing employment and competitiveness, and eliminating climate change and environmental problems are benefits of renewable energy sources [8].

Wind energy, which is the oldest energy source [3], is caused by the difference in pressure that occurs when the earth's surface is exposed to different solar rays [4]. Wind energy, which provides high usability, reliability, and clean energy, is one of the fastest growing renewable energy sources all over the world [9]. Wind energy is abundant, useful, and economical [1] compared to limited, expensive, and defective hydrocarbon based energy [5].

The increase of the urban population and the development of industry increased Turkey's energy needs [4]. Thanks to its geographical location, Turkey has an alternative renewable energy, especially wind energy [7]. It is important to establish where the power plant is to take advantage of this energy at the maximum level [5]. Political, social, environmental, cultural, and economic criteria should be considered in addition to the technical requirements for wind power plant site selection [10].

Multicriterion Decision Making (MCDM) methods are often used to solve wind power plant site selection problem 
including complex criterion [9]. MCDM methods widely used in solution of this problem are Analytic Network Process (ANP), Analytic Hierarchy Process (AHP), Elimination and Choice Translating Reality (ELECTRE), and Technique for Order Preference by Similarity to Ideal Solution (TOPSIS) [6].

In this study, the Intuitionistic Fuzzy TOPSIS (IFT) approach is proposed for the solution of the problem of wind power plant site selection. The most commonly used method for ranking alternatives based on criterion is TOPSIS [11]. The alternative chosen from all alternatives is the closest to the positive ideal solution, in other words the farthest away from the negative ideal solution. Positive ideal solution maximizes the benefit criterion and minimizes the cost criterion. It is the inverse for the negative ideal solution [12]. The IFS is used to deal with real life uncertainty, imprecision, vagueness, and linguistic human decisions. Also, it provides reflection of approval, rejection, and hesitation of decision makers [13].

In numerical example, 3 alternatives were selected for the wind power plant and the results of the literature survey were sorted according to the 10 election decisions determined. These criteria are gathered in 4 dimensions. Wind potential includes wind speed and wind density criterion. Location consists of surface characteristics, proximity, power distribution network, and natural disaster occurrence. In dimension of cost, there are land purchase cost and initial and annual maintenance. Finally, social benefits cover cultural and environmental concerns and employment.

The rest of this article is organized as follows: In Section 2, a literature search of the wind power site selection is given. Then the IFTOPSIS method is given in Section 3. In Section 4 this approach is illustrated with a numerical example. The conclusion and comment of the problem are given in Section 5 .

\section{Literature Review}

Increasing global warming and increased energy demand have led countries to use renewable energy sources. This study is about wind energy from renewable energy sources. Criterion and method for wind energy site selection have been determined by literature survey. Summaries of the literature study are given in Tables 1 and 2.

The work in [4] represents the importance of renewable energy sources and Turkey has a high potential for wind energy. The wind energy potential map has been examined and potential places in Amasra, Bandırma, Bozcaada, and Çanakkale have been selected. For site selection, surface characteristic, proximity, cost, and wind characteristic were chosen as the criteria for selection. Choquet integral method, which enables interaction between criteria and evaluates quantitative and qualitative data at the same time, is applied. Çanakkale was found as the most suitable alternative.

The authors of [3] have used an integrated hierarchical Data Envelopment Analysis (DEA) method for wind plant location optimization in their work and have implemented it in Iran. A total of 125 locations in 25 cities and 5 regions in each city were evaluated. In order to determine the best region at the first level of location optimization, land cost, population and human labor, and distances of power distribution networks indicators with social and technical structure were selected. At the second level in order to prioritize the cities used indicators, which have technical and geographical characteristics: intensity of natural disasters, quantity of proper topographical areas, quantity of proper geological areas, and average wind blow.

The authors of [6] have established a decision mechanism for SWHPS (solar-wind hybrid power station) site selection using AHP method. For the 49.5 MW SWHPS installation in China, the assessment committee chose business benefits, socioeconomic needs, and performances as subtargets and benefit, accessibility, environment, risk, and resource as evaluation features. Five alternative SWHPS sites are selected using the Geographic Information System (GIS) and grid map. As a result, alternative A site was chosen as the most suitable site.

The authors of [2] develop strategies for the selection of an offshore wind farm, in the coastal regions of South Korea's Jeju Island. The settlement criteria are divided into four categories: conservation areas and environmental protection, energy resources and economy, marine ecology and human activities, and marine environment. They have developed 4 scenarios for alternative site selection by utilizing GIS. In the scenario where 4 categories were taken into consideration, fewer suitable areas were found than other scenarios. But consideration of all categories will help to reduce the number of social conflicts among stakeholders and environmental issues by providing a sustainable and eco-friendly offshore wind farm.

The authors of [7] have done a study on site selection for wind energy plants. They choose Western Turkey as application area. The application consists of two stages: first stage is elimination of unfavorable stages and second stage is examination of existing ones. Alternative land areas are treated as grids of the same size, each large enough to build a wind turbine. GIS have been used to apply the elimination criterion and restrictions. Besides, Multiple Criterion Decision Analysis (MCDA) is then used to rank and sort the grids via the evaluation criterion specified. The problem has been assessed in 13 areas where several grids are assembled to evaluate larger areas of space to build wind farms instead of individual turbines. In all MCDA methods used, areas 3, 5, 8, and 12 are emphasized.

The authors of [5] used an integrated fuzzy-DEA approach in this study to decide on wind farm locations. They used the Basic Component Analysis (BCA) and Numerical Taxonomy (NT) methods to validate the results of the DEA model. The model was tested on 25 candidate cities in Iran with 5 regions in each city. In addition, 20 other cities are considered to be consumers of energy produced. The results show the importance of the proximity of consumers in the establishment of wind farms.

The authors of [1] evaluated the possibility of establishing wind farms in the province of Ardabil in northwestern Iran by combining ANP and Decision Making Experiment and Evaluation Laboratories (DEMATEL) methods in a GIS environment. Using the 13 layers of information according to three main criteria, environment, technical, and economical, 


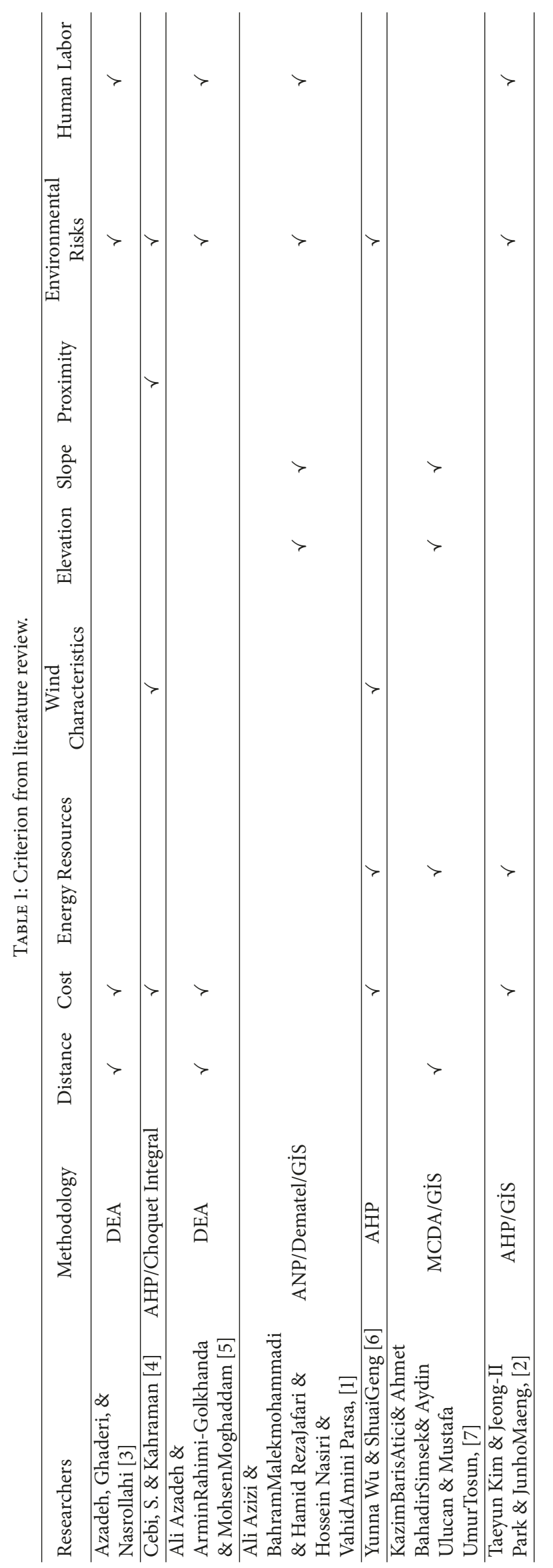


TABLE 2: Literature review on renewable energy location selection.

\begin{tabular}{|c|c|c|}
\hline Authors & Title of the Study & Article Name \\
\hline Azadeh, Ghaderi, \& Nasrollahi [3] & $\begin{array}{c}\text { Location optimization of wind plants in Iran by an integrated } \\
\text { hierarchical Data Envelopment Analysis. }\end{array}$ & Renewable Energy \\
\hline Cebi, S. \& Kahraman [4] & $\begin{array}{c}\text { Using Multi Attribute Choquet Integral in Site Selection of } \\
\text { Wind Energy Plants: The case of Turkey }\end{array}$ & $\begin{array}{l}\text { Journal of Multiple-Valued Logic } \\
\text { \& Soft Computing }\end{array}$ \\
\hline $\begin{array}{l}\text { Ali Azadeh \& } \\
\text { ArminRahimi-Golkhanda \& Mohsen } \\
\text { Moghaddam (2013) }\end{array}$ & $\begin{array}{l}\text { Location optimization of wind plants in Iran by an integrated } \\
\text { hierarchical data envelopment analysis. }\end{array}$ & Renewable Energy \\
\hline $\begin{array}{l}\text { Ali Azizi \& Bahram } \\
\text { Malekmohammadi \&Hamid Reza } \\
\text { Jafari \& Hossein Nasiri \& Vahid Amini } \\
\text { Parsa, [1] }\end{array}$ & $\begin{array}{l}\text { Land suitability assessment for wind power plant site } \\
\text { selection using ANP-DEMATEL in a GIS environment: case } \\
\text { study of Ardabil province, Iran. }\end{array}$ & Environ Monit Assess \\
\hline $\begin{array}{l}\text { Yunna Wu \& ShuaiGeng } \\
{[6]}\end{array}$ & $\begin{array}{c}\text { Multi-criterion decision making on selection of solar-wind } \\
\text { hybrid power station location }\end{array}$ & $\begin{array}{l}\text { A case of China Energy } \\
\text { Conversion and Management }\end{array}$ \\
\hline $\begin{array}{l}\text { KazimBarisAtici \& Ahmet } \\
\text { BahadirSimsek \& Aydin Ulucan \& } \\
\text { Mustafa UmurTosun, } \\
\text { [7] }\end{array}$ & $\begin{array}{l}\text { A GIS-based Multiple Criterion Decision Analysis approach } \\
\text { for wind power plant site selection. }\end{array}$ & Utilities Policy \\
\hline $\begin{array}{l}\text { Taeyun Kim \& Jeong-II Park \& } \\
\text { JunhoMaeng, [2] }\end{array}$ & $\begin{array}{l}\text { Offshore wind farm site selection study around Jeju Island, } \\
\text { South Korea. }\end{array}$ & Renewable Energy \\
\hline
\end{tabular}

a land suitability map was established. Then, it is reclassified according to the 5 equal-rate divisions from the most suitable areas that are least suitable. The results show that $6.68 \%$ of Ardabil province is most suitable for wind turbines.

\section{Methodology}

MCDM techniques are often used because mathematical and heuristic methods are inadequate in dealing with qualitative factors in the solution of the problem of location selection that has come up to date from the past and is still valid [4]. The MCDM methods are useful in reflecting the judgments of decision makers and in dealing with the complexity in the decision process [7].

The TOPSIS method of the MCDM techniques is proposed for solving the problem of wind power plant site selection. This section briefly reviews the intuitionistic fuzzy set and TOPSIS method.

3.1. Intuitionistic Fuzzy Set. Human decisions in real life problems involve uncertainty and ambiguity. In 1965, the fuzzy set theory was proposed by Zadeh to deal with this ambiguity and uncertainty [14]. The intuitionistic fuzzy set (A-IFS), which is generalized to the fuzzy set and characterized by a membership function and a nonmember function, was first introduced in 1986 by Atanassov. IFS has been applied to many different fields, including logic programming, medical diagnosis, decision making, evaluation function, and preference relation [15].

In this section a few definitions and operations of IFS are introduced.

Let $X$ be fixed. IFS $\mathrm{A}$ in $\mathrm{X}$ can be defined as

$$
X=\left\{s, \mu_{x}(s), v_{x}(s) \mid s \in S\right\}
$$

where

$$
\begin{array}{ll}
\mu_{\mathrm{x}}(\mathrm{s}): \mu_{\mathrm{x}}(\mathrm{s}) \in[0,1], & \mathrm{S} \longrightarrow[0,1] \\
\mathrm{v}_{\mathrm{x}}(\mathrm{s}): \mathrm{v}_{\mathrm{x}}(\mathrm{s}) \in[0,1], & \mathrm{S} \longrightarrow[0,1]
\end{array}
$$

$\mu_{\mathrm{x}}(\mathrm{s})$ and $\mathrm{v}_{\mathrm{x}}(\mathrm{s})$ are degrees of membership and nonmembership function, respectively, satisfying the following equation:

$$
0 \leq \mu_{\mathrm{x}}(\mathrm{s})+\mathrm{v}_{\mathrm{x}}(\mathrm{s}) \leq 1 \quad \forall \mathrm{s} \in \mathrm{S}, \mathrm{R} \longrightarrow[0,1]
$$

For the IFS A in $\mathrm{X}, \pi_{\mathrm{x}}(\mathrm{s})$ is defined as the intuitionistic index. It is the measurement of the hesitation degree.

$$
\pi_{\mathrm{x}}(\mathrm{s})=1-\mu_{\mathrm{x}}(\mathrm{s})-\mathrm{v}_{\mathrm{x}}(\mathrm{s}) .
$$

Let $A$ and $B$ be IFS of the set $S$; then the multiplication operators are, correspondingly,

$$
\begin{aligned}
\mathrm{X} & +\mathrm{Y} \\
& =\left\{\mu_{\mathrm{x}}(\mathrm{s}) * \mu_{\mathrm{y}}(\mathrm{s}), \mathrm{v}_{\mathrm{x}}(\mathrm{s})+\mathrm{v}_{\mathrm{y}}(\mathrm{s})-\mathrm{v}_{\mathrm{x}}(\mathrm{s}) * \mathrm{v}_{\mathrm{y}}(\mathrm{s}) \mid \in \mathrm{S}\right\}
\end{aligned}
$$

3.2. Intuitionistic Fuzzy TOPSIS. The TOPSIS, first introduced by Hwang and Yoon in 1981, is the most common method of ranking alternatives based on the selection criterion. The basic idea of the TOPSIS method is to rank the alternatives from best to worst. The best solution among the alternatives in the obtained order is the closest one to the positive ideal solution at the same time as the farthest negative solution [16].

Fuzzy numbers are used to deal with real life uncertainty, imprecision, vagueness, and linguistic human decisions. The intuitionistic fuzzy sets better reflect the decision makers' approval, rejection, and hesitation [17]. 
TABLE 3: Linguistic terms for rating DMs.

\begin{tabular}{lc}
\hline Linguistic terms & IFNs \\
\hline Very Important & $(0.80,0.10)$ \\
Important & $(0.50,0.20)$ \\
Medium & $(0.50,0.50)$ \\
Bad & $(0.30,0.50)$ \\
Very Bad & $(0.20,0.70)$ \\
\hline
\end{tabular}

In this section, we present an Intuitionistic Fuzzy TOPSIS model introduced by [13] for the evaluation of the alternatives. The order of $\mathrm{m}$ alternatives is based on $\mathrm{n}$ criterion. $\mathrm{A}=$ $\{\mathrm{A} 1, \mathrm{~A} 2, \ldots, \mathrm{Am}\}$ is set of alternatives, $\mathrm{C}=\{\mathrm{C} 1, \mathrm{C} 2, \ldots, \mathrm{Cn}\}$ is set of criteria, and $\mathrm{L}=\{11,12, \ldots, 11\}$ represents set of decision makers.

Now we replace the algorithm with a seven-step procedure as follows.

Step 1 (calculate the weights of DMs). The importance of the DMs is represented as linguistic terms (Table 3 ).

$\mathrm{Dl}=[\mu 1, \nu 1, \pi \mathrm{l}]$ is the intuitionistic fuzzy number for lth $\mathrm{DM}$ ranking. The weight of DM can be determined by the following formula:

$$
\lambda l=\frac{[\mu l+\pi l(\mu l /(\mu l+v l))]}{\sum_{l=1}^{k}[\mu l+\pi l(\mu l /(\mu l+v l))]}
$$

where

$$
\lambda_{1} \in[0,1] \text { and } \sum_{l=1}^{k} \lambda \mathrm{l}=1
$$

Step 2 (calculate the weights of criterion). All criteria can not be regarded as having equal qualification. W represents a set of importance levels. In order to achieve $\mathrm{W}$, all DM views on the importance of each criterion need to be integrated.

Let $\mathrm{w}_{j}^{k}=\left(\mu_{j}^{k}, v_{j}^{k}, \pi_{j}^{k}\right)$ represent intuitionistic fuzzy number about the $\mathrm{Xj}$ criterion of the kth decision maker. The intuitionistic fuzzy weighted averaging (IFWA) operator is used to calculate the weights of the criterion. The IFWA operator is developed by $\mathrm{Xu}$ (2007).

$$
\begin{gathered}
\mathrm{w}_{\mathrm{j}}=\operatorname{IFWAr}_{\lambda}\left(w_{j}^{(1)}, w_{j}^{(2)}, \ldots w_{j}^{(l)}\right)=\lambda_{1} w_{j}^{(1)} \oplus \lambda_{2} w_{j}^{(2)} \\
\oplus, \ldots, \oplus \lambda_{\mathrm{k}} w_{j}^{(l)}=\left[1-\prod_{l=1}^{k}\left(1-\mu_{i j}^{(l)}\right)^{\lambda \mathrm{l}},\right. \\
\left.\prod_{l=1}^{k}\left(v_{i j}^{(l)}\right)^{\lambda \mathrm{l}}, \prod_{l=1}^{k}\left(1-\mu_{i j}^{(l)}\right)^{\lambda \mathrm{l}}-\prod_{l=1}^{k}\left(1-v_{i j}^{(l)}\right)^{\lambda \mathrm{l}}\right]
\end{gathered}
$$

The importance of criterion is represented as linguistic terms (Table 4).

Step 3 (construct intuitionistic fuzzy decision matrix (IFDM)). To arrive at a precise conclusion, each view from a group of DMs must be combined into a single view to form the aggregated intuitionistic fuzzy decision matrix (AIFDM) model.
TABLE 4: Linguistic terms for rating criterion.

\begin{tabular}{lc}
\hline Linguistic terms & IFNs \\
\hline Very Important & $(0.90,0.10)$ \\
Important & $(0.75,0.20)$ \\
Medium & $(0.50,0.45)$ \\
Unimportant & $(0.35,0.60)$ \\
Very Unimportant & $(0.10,0.90)$ \\
\hline
\end{tabular}

Let $\mathrm{R}^{(1)}=\left(r_{i j}^{(1)}\right)_{\mathrm{m} * \mathrm{n}}$ be the IFDM of each DM.

$\lambda=\left\{\lambda_{1}, \lambda_{2}, \lambda_{3}, \ldots, \lambda_{\mathrm{k}}\right\}$ is the weight of the DM.

$$
\mathrm{R}=\left(\mathrm{r}_{\mathrm{ij}}\right)_{\mathrm{m}^{\prime} * \mathrm{n}^{\prime}}
$$

where

$$
\begin{aligned}
& \mathrm{r}_{\mathrm{ij}}=\operatorname{IFWAr}_{\lambda}\left(r_{i j}^{(1)}, r_{i j}^{(2)}, \ldots r_{i j}^{(k)}\right)=\lambda_{1} r_{i j}^{(1)} \oplus \lambda_{2} r_{i j}^{(2)} \oplus, \ldots, \\
& \oplus \lambda_{\mathrm{k}} r_{i j}^{(k)}=\left[1-\prod_{l=1}^{k}\left(1-\mu_{i j}^{(l)}\right)^{\lambda l},\right. \\
&\left.\prod_{l=1}^{k}\left(v_{i j}^{(l)}\right)^{\lambda \mathrm{l}}, \prod_{l=1}^{k}\left(1-\mu_{i j}^{(l)}\right)^{\lambda l}-\prod_{l=1}^{k}\left(1-v_{i j}^{(l)}\right)^{\lambda l}\right]
\end{aligned}
$$

Step 4 (the calculation of aggregated weighted intuitionistic fuzzy decision matrix (AWIFDM)). The aggregated weighted intuitionistic fuzzy decision matrix is calculated by combining $\mathrm{W}$ and $\mathrm{R}$.

$$
\begin{aligned}
\mathrm{R} \oplus \mathrm{W} & =\left(\mu_{i j}^{\prime}, v_{i j}^{\prime}\right) \\
& =\left\{\left\langle x, \mu_{i j} * \mu_{j}, v_{i j}+v_{j}-v_{i j} * v_{j}\right\rangle\right\} \\
\pi_{i j}^{\prime} & =1-\mu_{i j} * \mu_{j}-v_{i j}-v_{j}+v_{i j} * v_{j}
\end{aligned}
$$

Step 5 (calculate intuitionistic fuzzy positive and negative ideal solution). Let $\mathrm{J}_{1}$ be benefit criterion and $\mathrm{J}_{2}$ be cost criterion. $A^{*}$ represents intuitionistic fuzzy positive ideal solution and $A^{-}$represents intuitionistic fuzzy negative ideal solution. Then $\mathrm{A}^{*}$ and $A^{-}$are calculated as

$$
\begin{aligned}
& A^{*}=\left(r_{1}^{\prime^{*}}, r_{2}^{\prime^{*}}, \ldots, r_{n}^{\prime^{*}}\right), \\
& r_{j}^{\prime^{*}}=\left(\mu_{j}^{\prime^{*}}, v_{j}^{\prime^{*}}, \pi_{j}^{\prime^{*}}\right), \quad j=1,2, \ldots, n \\
& A^{-}=\left(r_{1}^{\prime^{-}}, r_{2}^{\prime^{-}}, \ldots, r_{n}^{\prime^{-}}\right), \\
& r_{j}^{\prime^{-}}=\left(\mu_{j}^{\prime^{-}}, v_{j}^{\prime^{-}}, \pi_{j}^{\prime^{-}}\right), \quad j=1,2, \ldots, n
\end{aligned}
$$


where

$$
\begin{aligned}
& \mu_{j}^{\prime^{*}}=\left\{\left(\max _{i}\left\{\mu_{i j}^{\prime}\right\} j \in J_{1}\right),\left(\min _{i}\left\{\mu_{i j}^{\prime}\right\} j \in J_{2}\right)\right\}, \\
& \mathrm{v}_{j}^{\prime^{*}}=\left\{\left(\min _{i}\left\{v_{i j}^{\prime}\right\} j \in J_{1}\right),\left(\max _{i}\left\{v_{i j}^{\prime}\right\} j \in J_{2}\right)\right\}, \\
& \pi_{j}^{\prime^{*}}=\left\{\left(1-\max _{i}\left\{\mu_{i j}^{\prime}\right\}-\min _{i}\left\{v_{i j}^{\prime}\right\} j \in J_{1}\right),\right. \\
& \left.\mu_{j}^{\prime^{-}}=\left\{\left(\min _{i}\left\{\mu_{i j}^{\prime}\right\}-\max _{i}\left\{\mu_{i j}^{\prime}\right\} j \in J_{i j}\right\} \in J_{1}\right),\left(\max _{i}\left\{\mu_{i j}^{\prime}\right\} j \in J_{2}\right)\right\}, \\
& \mathrm{v}_{j}^{\prime^{-}}=\left\{\left(\max _{i}\left\{v_{i j}^{\prime}\right\} j \in J_{1}\right), \min _{i}\left\{v_{i j}^{\prime}\right\} j \in J_{2}\right\}, \\
& \pi_{j}^{\prime^{-}}=\left\{\left(1-\min _{i}\left\{\mu_{i j}^{\prime}\right\}-\max _{i}\left\{v_{i j}^{\prime}\right\} j \in J_{1}\right),\right. \\
& \left.\left(1-\max _{i}\left\{\mu_{i j}^{\prime}\right\}-\min _{i}\left\{v_{i j}^{\prime}\right\} j \in J_{2}\right),\right\}
\end{aligned}
$$

Step 6 (obtain the separation measures between the alternatives). In this paper, the normalized Euclidean distance proposed by Szmidt and Kacprzyk (2000) is used for measure separation between alternatives on intuitionistic fuzzy set. $\mathrm{Si}^{*}$ and $\mathrm{Si}^{-}$, the separation measures of each alternative, are calculated for intuitionistic fuzzy positive ideal and negative ideal solutions, respectively.

$$
\begin{aligned}
& S_{i}^{*} \\
& =\sqrt{\frac{1}{2 n} \sum_{j=1}^{n}\left[\left(\mu_{i j}^{\prime}-\mu_{j}^{\prime *}\right)^{2}+\left(v^{\prime}{ }_{i j}-\mathrm{v}_{j}^{\prime *}\right)^{2}+\left(\pi^{\prime}{ }_{i j}-\pi_{j}^{\prime *}\right)^{2}\right]}, \\
& S_{i}^{-} \\
& =\sqrt{\frac{1}{2 n} \sum_{j=1}^{n}\left[\left(\mu_{i j}^{\prime}-\mu_{j}^{\prime}\right)^{2}+\left(v_{i j}^{\prime}-\mathrm{v}_{j}^{\prime}\right)^{2}+\left(\pi_{i j}^{\prime}-\pi_{j}^{\prime}\right)^{2}\right]},
\end{aligned}
$$

Step 7 (determine the final ranking). The relative closeness coefficient of an alternative $A_{i}$ with respect to the intuitionistic fuzzy positive ideal solution $A^{*}$ is defined as follows:

$$
C C_{i}^{*}=\frac{S_{i}^{-}}{S_{i}^{*}+S_{i}^{-}}, \quad \text { where } 0 \geq C_{i}^{*} \leq 1 .
$$

After the relative closeness coefficient of each alternative is determined, alternatives are ranked according to descending order of $\mathrm{CCi}^{*}$.

\section{Case Study}

In this section, the IFTOPSIS method for selection of appropriate wind power plant site is applied in a numerical example. It is shown in Figure 1. A decision maker group consisting of three experts was formed for this reason. Decision maker 1 is a geographer, decision maker 2 is a map engineer, and decision maker 3 is an energy engineer. Çanakkale, İzmir, Samsun, and Mersin are selected as the alternative for wind power plant location. Three decision makers evaluate these alternatives and for selection of an appropriate alternative we will use selection criterion given in Table 6. Ten criteria are considered as follows.

Wind speed (C1): this includes a high average wind speed and the ability to provide the maximum benefit from the wind.

Wind density (C2): it is the kinetic energy measure produced by wind, unit square meter and time.

Surface characteristic (C3): this includes geological conditions such as soil structure and infrastructure conditions and topographic conditions such as geographical direction, elevation of the plant, and slope which are properties to be taken into consideration in the site selection.

Proximity (C4): due to some factors such as noise pollution, healthcare, aesthetics, and safety, the wind power plant should be away from areas such as urban areas, water resource, main roads, protected areas, and airports.

Power distribution network (C5): to prevent energy losses, the plant must be installed in areas close to the consumers.

Natural disaster occurrence (C6): this criterion is aimed at establishing the plant in places where safe and natural disasters are less experienced.

Land purchase cost (C7): this criterion refers to the purchase cost of the place where the plant will be established.

Initial and annual maintenance cost (C8): installation and annual maintenance costs are the criteria that should not be ignored.

Cultural end environmental concerns (C9): the plant to be installed must not be allowed to harm the environment and the historical heritage.

Employment (C10): being close to the available human labor of the plant is important in terms of employee accommodation and salaries.

4.1. Application of Intuitionistic Fuzzy TOPSIS Method. In this section, Intuitionistic Fuzzy TOPSIS model is applied for the evaluation of the alternatives.

In Step 1, the linguistic terms in Table 3 and (7) are used to calculate the weight of the decision makers and the results in Table 7 were obtained.

In the second step, the opinions of the decision makers about the criterion weight are calculated as shown in Table 10 using Table 4 and (9).

Decision makers were asked to evaluate each alternative using linguistic terms in Table 5 for each criterion and Table 8 was generated. Using (11), Table 11 is calculated, so that the decisions of DMs are collected into a single decision. 


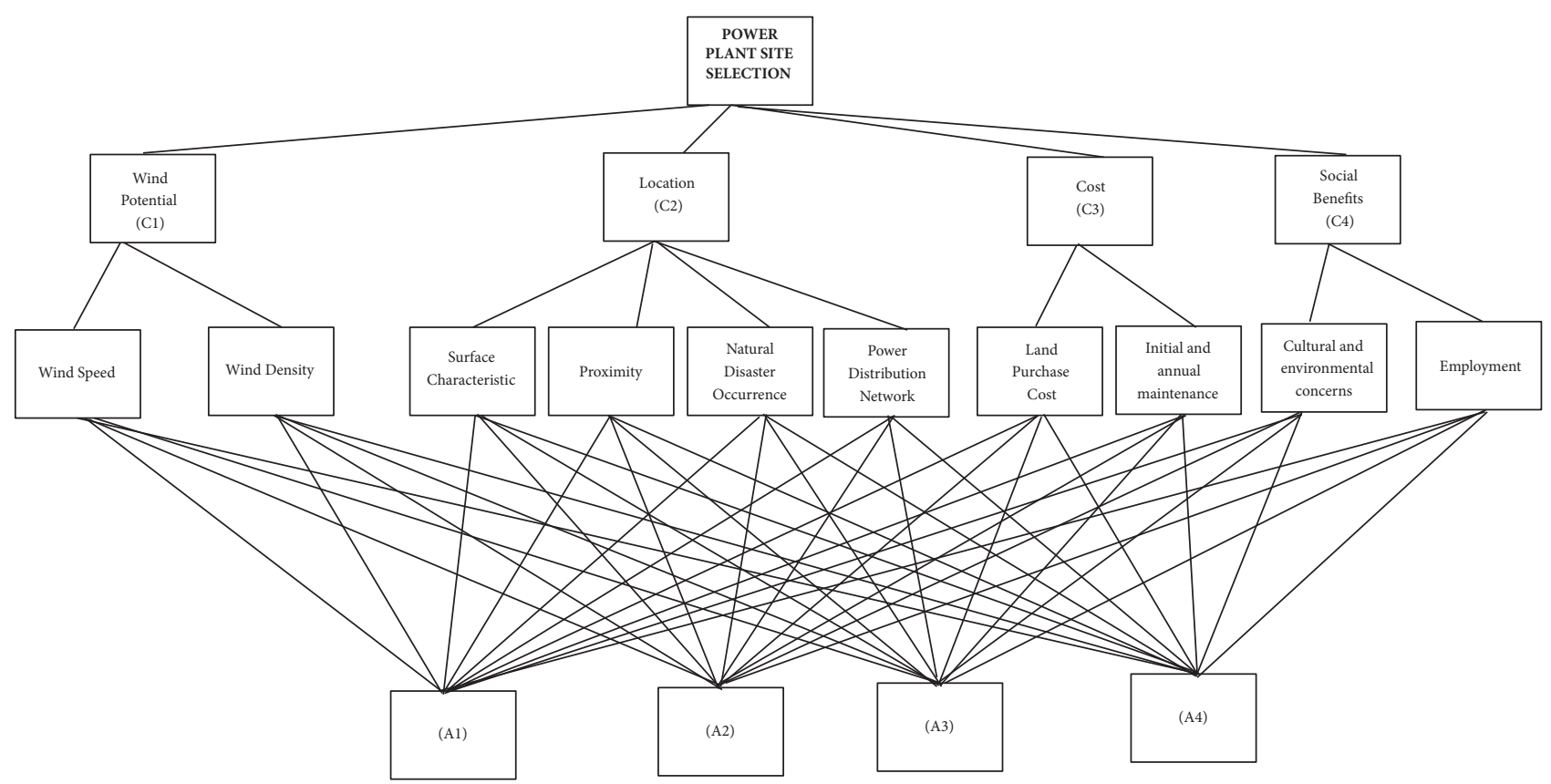

FIGURE 1: Alternative assessment based on criterion.

TABLE 5: Linguistic terms for rating the alternatives.

\begin{tabular}{lc}
\hline Linguistic terms & IFNs \\
\hline Very Good (VG) & {$[1.00,0.00,0.00]$} \\
Good (G) & {$[0.85,0.05,0.10]$} \\
Moderately Good (MG) & {$[0.70,0.20,0.10]$} \\
Fair (F) & {$[0.50,0.50,0.00]$} \\
Moderately Poor (Mp) & {$[0.40,0.50,0.10]$} \\
Poor (P) & {$[0.25,0.60,0.15]$} \\
Very Poor (VP) & {$[0.00,0.90,0.10]$} \\
\hline
\end{tabular}

TABle 6: The dimension and criterion of wind power plant site selection.

\begin{tabular}{lcl}
\hline Target & Dimension & Criterion \\
\hline & Wind Potential & Wind speed \\
& & Wind density \\
& Surface characteristic \\
& & Proximity \\
Wind power & Location & Power distribution network \\
plant site & & Natural disaster occurrence \\
selection & & Land purchase cost \\
& & Initial and annual maintenance \\
& & cost \\
& & Cultural end environmental \\
& & concerns \\
& & Employment \\
\hline
\end{tabular}

By combining the criterion weights and the aggregated intuitionistic fuzzy decision matrix with the help of (12) and (13), an aggregated weighted intuitionistic fuzzy decision matrix is obtained in Table 12.
TABLE 7: The importance and weights of decision makers' opinions.

\begin{tabular}{lccc}
\hline & DM1 & DM2 & DM3 \\
\hline Linguistic terms & Very Important & Important & Medium \\
$\lambda$ & 0,42 & 0,34 & 0,24 \\
\hline
\end{tabular}

In Step 5 from AIFMD, $\mathrm{A}^{+}$is calculated by using (16), (17), and (18) and $\mathrm{A}^{-}$is calculated by using (19), (20), and (21). $\mathrm{A}^{+}$ and $\mathrm{A}^{-}$are shown that in Table 13 and in Table 14, respectively.

To calculate $S^{*}(22)$ is used, to calculate $S^{-}(23)$ is used, and to calculate $C C_{i}^{*}(24)$ is used. $S^{*}$ and $S^{-}$represent separation measurement and $C C_{i}^{*}$ shows ranking of alternatives. $S^{*} S^{-}$and $C C_{i}^{*}$ values for the alternatives are determined and presented in Table 15.

4.2. Application of Fuzzy TOPSIS Method. In this section, the data used in the solution phase of the Intuitionistic Fuzzy TOPSIS model (decision makers opinions, importance weight of the criterion) were also used in Fuzzy TOPSIS application. As a result of this evaluation, the results obtained by the two different approaches under the same data will be compared and the effectiveness and solution results of the proposed Intuitionistic Fuzzy TOPSIS model will be evaluated.

After obtaining fuzzy ratings from Tables 9 and 10 normalized fuzzy decision matrix determined is shown in Table 16.

By combining the criterion weights and the aggregated Intuitionistic fuzzy decision matrix, aggregated weighted intuitionistic fuzzy decision matrix is obtained. After that, fuzzy positive ideal solution $\left(A^{+}\right)$and negative ideal solution $\left(A^{-}\right)$obtained according to the aggregated weighted intuitionistic fuzzy decision matrix are presented in Tables 17 and 18 , respectively. 
TABLE 8: Importance of alternative based on opinion of DMs.

\begin{tabular}{|c|c|c|c|c|c|c|c|c|c|c|c|}
\hline \multirow[t]{2}{*}{ Decision-Makers (DMs) } & \multirow[t]{2}{*}{ Alternative } & \multicolumn{10}{|c|}{ Criterion } \\
\hline & & $\mathrm{Cl}$ & $\mathrm{C} 2$ & $\mathrm{C3}$ & $\mathrm{C} 4$ & C5 & C6 & $\mathrm{C} 7$ & $\mathrm{C8}$ & C9 & $\mathrm{C10}$ \\
\hline \multirow{4}{*}{ DM1 } & Mersin & MG & G & MP & MG & MG & MG & G & MP & $\mathrm{F}$ & $\mathrm{P}$ \\
\hline & Çanakkale & VG & VG & G & VG & G & MP & MG & MG & MP & $\mathrm{MP}$ \\
\hline & İzmir & VG & VG & $\mathrm{F}$ & G & VG & $\mathrm{F}$ & $\mathrm{F}$ & G & MG & MG \\
\hline & Samsun & G & $\mathrm{F}$ & MG & MP & $\mathrm{F}$ & G & VG & $\mathrm{F}$ & $\mathrm{P}$ & $\mathrm{F}$ \\
\hline \multirow{4}{*}{ DM2 } & Mersin & MG & G & $\mathrm{F}$ & $\mathrm{F}$ & $\mathrm{F}$ & G & VG & $\mathrm{F}$ & MP & $\mathrm{P}$ \\
\hline & Çanakkale & VG & VG & MG & MG & VG & $\mathrm{F}$ & MG & G & G & MG \\
\hline & İzmir & G & G & G & G & G & MP & $\mathrm{F}$ & MG & MG & $\mathrm{F}$ \\
\hline & Samsun & MG & MG & MP & MP & MG & MG & G & MP & $\mathrm{F}$ & MP \\
\hline \multirow{4}{*}{ DM3 } & Mersin & $\mathrm{F}$ & MG & MP & MP & $\mathrm{F}$ & $\mathrm{F}$ & G & $\mathrm{F}$ & $\mathrm{MP}$ & $\mathrm{P}$ \\
\hline & Çanakkale & VG & VG & MG & G & G & $\mathrm{MP}$ & MG & G & MG & F \\
\hline & İzmir & G & VG & G & MG & VG & $\mathrm{P}$ & $\mathrm{MP}$ & MG & $\mathrm{F}$ & $\mathrm{G}$ \\
\hline & Samsun & MG & $\mathrm{F}$ & $\mathrm{F}$ & $\mathrm{F}$ & MG & MG & $\mathrm{F}$ & VG & $\mathrm{P}$ & MG \\
\hline
\end{tabular}

TABLE 9: The importance weight of the criterion.

\begin{tabular}{lccc}
\hline Criterion & DM1 & DM2 & DM3 \\
\hline C1 & I & VI & I \\
C2 & VI & VI & VI \\
C3 & I & M & M \\
C4 & M & U & M \\
C5 & M & I & M \\
C6 & I & I & M \\
C7 & VI & I & VI \\
C8 & U & M & I \\
C9 & VU & U & U \\
C10 & $M$ & U & U \\
\hline
\end{tabular}

TABLE 10: Weight of criterion.

\begin{tabular}{ll}
\hline C1 & $(0.82,0.16,0.03)$ \\
C2 & $(0.90,0.10,0.00)$ \\
C3 & $(0.63,0.32,0.05)$ \\
C4 & $(0.45,0.50,0.05)$ \\
C5 & $(0.60,0.34,0.05)$ \\
C6 & $(0.70,0.24,0.05)$ \\
C7 & $(0.86,0.13,0.01)$ \\
C8 & $(0.53,0.42,0.05)$ \\
C9 & $(0.25,0.71,0.03)$ \\
C10 & $(0.42,0.53,0.05)$ \\
\hline
\end{tabular}

The calculation of distance $\left(S^{*}\right.$ and $\left.S^{-}\right)$of each alternative from $A^{+}$and $A^{-}$is determined. Then, by using the $\left(S^{*}\right.$ and $\left.S^{-}\right)$ values closeness coefficient $\left(C C_{i}^{*}\right)$ of each alternative is calculated and shown in Table 19. According to the obtained results, Canakkale is the best alternative and Samsun is the worst alternative.

4.3. Comparison of Intuitionistic Fuzzy TOPSIS with Fuzzy TOPSIS Method. In this section, the results obtained by two different methods will be compared. As Table 20 and

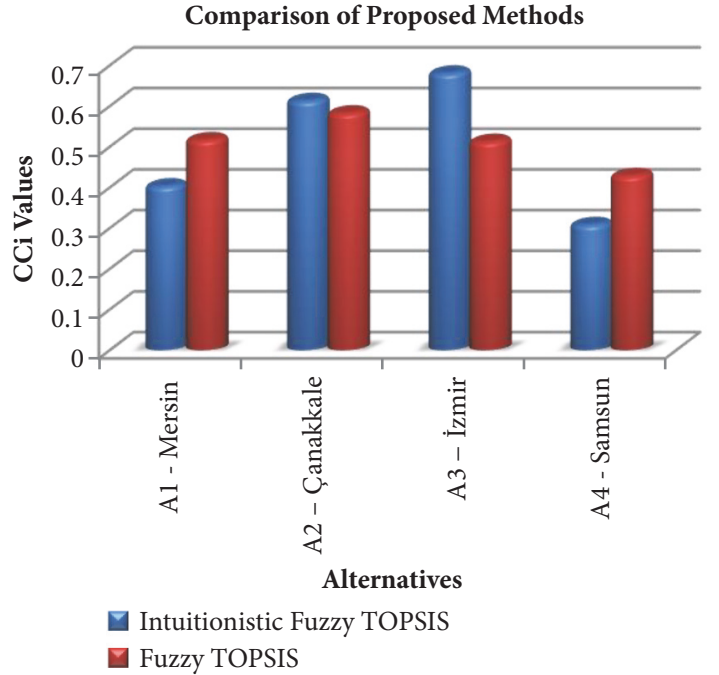

FIgURE 2: Comparison of two different methods results.

Figure 2 show the results obtained by Intuitionistic Fuzzy TOPSIS method and Fuzzy TOPSIS method, according to the Intuitionistic Fuzzy TOPSIS method the most important alternative is Izmir. Later, Çanakkale, Mersin, and Samsun are listed, respectively. According to the results obtained by Fuzzy TOPSIS method, Çanakkale is the most important alternative, followed by Mersin, Izmir, and Samsun, respectively.

Given the results obtained, it is clear how effective the weighting of decision makers' opinions is on the outcome, which demonstrates the effectiveness of the proposed method.

\section{Conclusion}

Many reasons, such as reduced resources, increased environmental problems, and energy need, have led the world to trend to renewable energy. The wind energy is from renewable energy that develops rapidly all around the world. To get the maximum benefit from wind energy, where the 


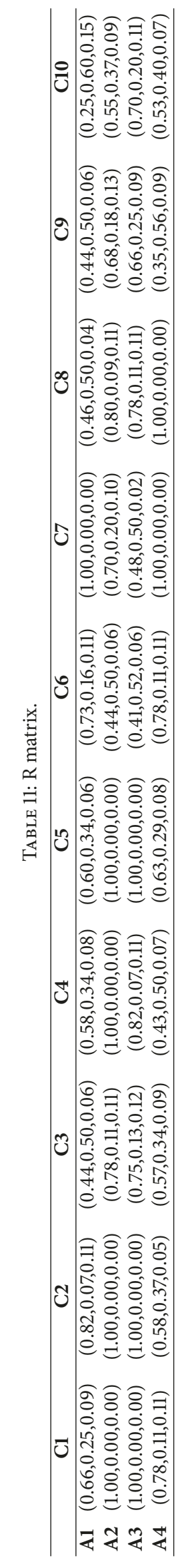




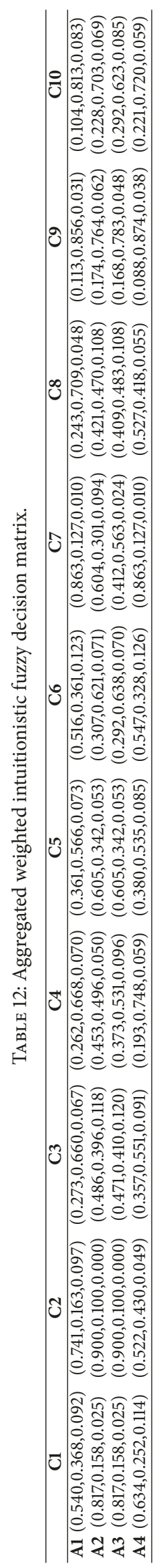


TABLE 13: $\mathrm{A}^{+}$.

\begin{tabular}{lc}
\hline C1 & $(0.817,0.158,0.025)$ \\
C2 & $(0.900,0.100,0.000)$ \\
C3 & $(0.486,0.396,0.118)$ \\
C4 & $(0.453,0.496,0.050)$ \\
C5 & $(0.605,0.342,0.053)$ \\
C6 & $(0.547,0.328,0.126)$ \\
C7 & $(0.412,0.563,0.024)$ \\
C8 & $(0.243,0.709,0.048)$ \\
C9 & $(0.174,0.764,0.062)$ \\
C10 & $(0.292,0.623,0.085)$ \\
\hline
\end{tabular}

TABLe 14: $\mathrm{A}^{-}$

\begin{tabular}{lr}
\hline C1 & $(0.540,0.368,0.092)$ \\
C2 & $(0.522,0.430,0.049)$ \\
C3 & $(0.273,0.660,0.067)$ \\
C4 & $(0.193,0.748,0.059)$ \\
C5 & $(0.361,0.566,0.073)$ \\
C6 & $(0.292,0.638,0.070)$ \\
C7 & $(0.863,0.127,0.010)$ \\
C8 & $(0.527,0.418,0.055)$ \\
C9 & $(0.088,0.874,0.038)$ \\
C10 & $(0.104,0.813,0.083)$ \\
\hline
\end{tabular}

TABLE 15: Separation measures and the relative closeness coefficient of each alternative.

\begin{tabular}{lccc}
\hline Alternatives & $\mathrm{S}^{*}$ & $\boldsymbol{S}^{-}$ & $\boldsymbol{C C}_{\boldsymbol{i}}^{*}$ \\
\hline Mersin & 0,2166 & 0,1466 & 0,4036 \\
Çanakkale & 0,1342 & 0,2131 & 0,6135 \\
İzmir & 0,1136 & 0,2425 & 0,6811 \\
Samsun & 0,2409 & 0,1075 & 0,3086 \\
\hline
\end{tabular}

plant is installed is a very important decision that needs to be taken. In addition to cost, many factors such as sustainability and the environment must be considered. Therefore, the wind power station site selection problem should be considered as MCDM problem.

In this paper, to solve problem of wind power plant site selection, the TOPSIS method is used and combined with the intuitionistic fuzzy number which is reflecting the judgments of decision makers and dealing with the complexity in the decision process, so that more accurate results can be achieved. Wind potential, location, cost, and social benefits were defined as dimension of criterion and the ten selected criteria were collected under these dimensions. The weights of the criterion importance were decided in the establishment of the wind power plant and the selection was made in this direction. The alternatives evaluated based on these criteria are Mersin, Çanakkale, İzmir, and Samsun. The results have shown that Izmir is the best alternative for wind power site.
Also Çanakkale, Mersin, and Samsun follow it, respectively. Thus which alternative is most appropriate is determined.

For the future research, the other MCDM methodologies like ELECTRE, PROMETHEE, etc. can be used for wind power site selection and the obtained results can be compared with ours. Furthermore, a comprehensive study can be carried out by identifying other main criteria and separating them with subcriterion.

\section{Data Availability}

The data used to support the findings of this study are available from the corresponding author upon request.

\section{Conflicts of Interest}

The authors declare that they have no conflicts of interest. 


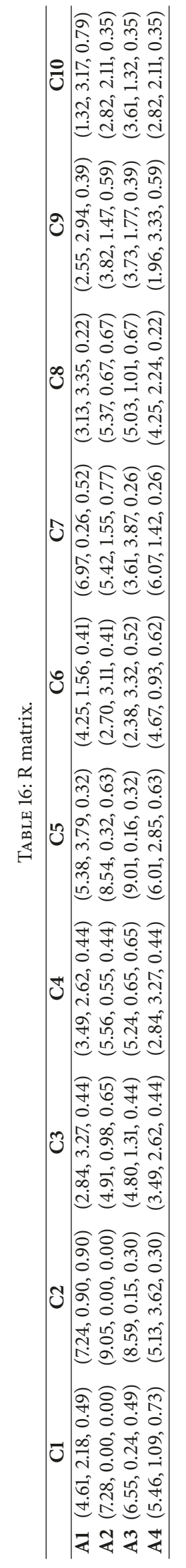


TABLE 17: $\mathrm{A}^{+}$positive distance of alternatives.

\begin{tabular}{lcccccccccc}
\hline ALTERNATIVES & C1 & C2 & C3 & C4 & C5 & C6 & C7 & C8 & C9 & C10 \\
\hline A1 & 0,726 & 0,550 & 0,433 & 0,331 & 0,733 & 0,173 & 0,153 & 0,393 & 0,143 & 0,319 \\
A2 & 0,115 & 0,121 & 0,244 & 0,451 & 0,407 & 0,682 & 0,457 & 0,374 & 0,442 & 0,217 \\
A3 & 0,223 & 0,178 & 0,211 & 0,436 & 0,414 & 0,570 & 0,966 & 0,332 & 0,372 & 0,328 \\
A4 & 0,499 & 1,176 & 0,304 & 0,412 & 0,615 & 0,872 & 0,280 & 0,251 & 0,158 & 0,217 \\
\hline
\end{tabular}

TABLE 18: $\mathrm{A}^{-}$negative distance of alternatives.

\begin{tabular}{lcccccccccc}
\hline ALTERNATIVES & C1 & C2 & C3 & C4 & C5 & C6 & C7 & C8 & C9 & C10 \\
\hline A1 & 0,115 & 0,634 & 0,244 & 0,357 & 0,414 & 0,441 & 0,966 & 0,374 & 0,352 & 0,328 \\
A2 & 0,726 & 1,176 & 0,433 & 0,412 & 0,638 & 0,191 & 0,523 & 0,393 & 0,158 & 0,251 \\
A3 & 0,529 & 1,040 & 0,411 & 0,363 & 0,733 & 0,193 & 0,153 & 0,337 & 0,165 & 0,319 \\
A4 & 0,238 & 0,121 & 0,222 & 0,451 & 0,332 & 0,536 & 0,708 & 0,294 & 0,442 & 0,251 \\
\hline
\end{tabular}

TABLE 19: Separation measures and the relative closeness coefficient of each alternative.

\begin{tabular}{lcccc}
\hline Alternatives & $\boldsymbol{S}^{*}$ & $\boldsymbol{S}^{-}$ & $\boldsymbol{C C}_{\boldsymbol{i}}^{*}$ & Ranking $^{-}$ \\
\hline A1 - Mersin & 3,9545 & 4,2258 & 0,517 & 2 \\
A2 - Çanakkale & 3,5102 & 4,9020 & 0,583 & 1 \\
A3 - İzmir & 4,0305 & 4,2441 & 0,513 & 3 \\
A4 - Samsun & 4,7853 & 3,5938 & 0,429 \\
\hline
\end{tabular}

TABLE 20: Comparison of the relative closeness coefficient of two methods.

\begin{tabular}{lccc}
\hline Alternatives & Intuitionistic Fuzzy TOPSIS CC & Ranking $_{\boldsymbol{i}}$ & Fuzzy $_{\text {TOPSIS CC }}$ \\
\hline A1 - Mersin & 0,4036 & 3 & 0,517 \\
A2 - Çanakkale & 0,6135 & 2 & 0,583 \\
A3 - İzmir & 0,6811 & 1 & 0,513 \\
A4 - Samsunking & 0,3086 & 4 & 0,429 \\
\hline
\end{tabular}

\section{References}

[1] A. Azizi, B. Malekmohammadi, H. R. Jafari, H. Nasiri, and V. Amini Parsa, "Land suitability assessment for wind power plant site selection using ANP-DEMATEL in a GIS environment: case study of Ardabil province, Iran," Environmental Modeling \& Assessment, vol. 186, no. 10, pp. 6695-6709, 2014.

[2] T. Kim, J.-I. Park, and J. Maeng, "Offshore wind farm site selection study around Jeju Island, South Korea," Renewable Energy, vol. 94, pp. 619-628, 2016.

[3] A. Azadeh, S. F. Ghaderi, and M. R. Nasrollahi, "Location optimization of wind plants in Iran by an integrated hierarchical Data Envelopment Analysis," Renewable Energy, vol. 36, no. 5, pp. 1621-1631, 2011.

[4] S. Cebi and C. Kahraman, "Using multi attribute choquet integral in site selection of wind energy plants: The case of turkey," Journal of Multiple-Valued Logic and Soft Computing, vol. 20, no. 5-6, pp. 423-443, 2013.

[5] A. Azadeh, A. Rahimi-Golkhandan, and M. Moghaddam, "Location optimization of wind power generation-transmission systems under uncertainty using hierarchical fuzzy DEA: A case study," Renewable and Sustainable Energy Reviews, vol. 30, pp. 877-885, 2014

[6] W. Yunna and S. Geng, "Multi-criterion decision making on selection of solar-wind hybrid power station location: A case of China," Energy Conversion and Management, vol. 81, pp. 527533, 2014

[7] K. B. Atici, A. B. Simsek, A. Ulucan, and M. U. Tosun, "A GISbased Multiple Criterion Decision Analysis approach for wind power plant site selection," Utilities Policy, vol. 37, pp. 86-96, 2015.

[8] T. Tsoutsos, I. Tsitoura, D. Kokologos, and K. Kalaitzakis, "Sustainable siting process in large wind farms case study in Crete," Renewable Energy, vol. 75, pp. 474-480, 2015.

[9] D. Latinopoulos and K. Kechagia, "A GIS-based multi-criterion evaluation for wind farm site selection. A regional scale application in Greece," Renewable Energy, vol. 78, pp. 550-560, 2015.

[10] Z. Aljicevic, A. Kostic, N. Dautbasic, and G. Karli, "Model of Fuzzy Logic for Selection Infrastructural Investment Project of Wind Farm Locations," in Proceedings of the, 2016, https://doi.org/10.2507/27th.daaam.proceedings.107.

[11] H. Gupta and M. K. Barua, "Supplier selection among SMEs on the basis of their green innovation ability using BWM and fuzzy 
TOPSIS," Journal of Cleaner Production, vol. 152, pp. 242-258, 2017.

[12] A. Zouggari and L. Benyoucef, "Simulation based fuzzy TOPSIS approach for group multi-criteria supplier selection problem," Engineering Applications of Artificial Intelligence, vol. 25, no. 3, pp. 507-519, 2012.

[13] B. D. Rouyendegh, "Developing an Integrated ANP and Intuitionistic Fuzzy TOPSIS Model for Supplier Selection," Journal of Testing and Evaluation, vol. 43, no. 3, p. 20130114, 2015.

[14] K. Devi and S. P. Yadav, "A multicriterion intuitionistic fuzzy group decision making for plant location selection with ELECTRE method," nternational Journal of Advanced Manufacturing Technology, vol. 66, no. 9-12, pp. 1219-1229.

[15] M.-C. Wu and T.-Y. Chen, "The ELECTRE multicriterion analysis approach based on Atanassovs intuitionistic fuzzy sets," Expert Systems with Applications, vol. 38, no. 10, pp. 12318-12327, 2011.

[16] H. Gupta and M. K. Barua, "Supplier selection among SMEs on the basis of their green innovation ability using BWM and fuzzy TOPSIS," Journal of Cleaner Production, vol. 152, no. 0, pp. 242258, 2017.

[17] Y. Wu, J. Zhang, J. Yuan, S. Geng, and H. Zhang, "Study of decision framework of offshore wind power station site selection based on ELECTRE-III under intuitionistic fuzzy environment: A case of China," Energy Conversion and Management, vol. 113, pp. 66-81, 2016. 


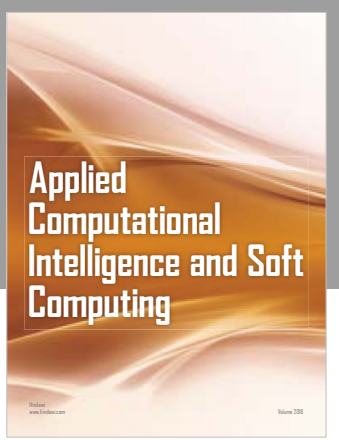

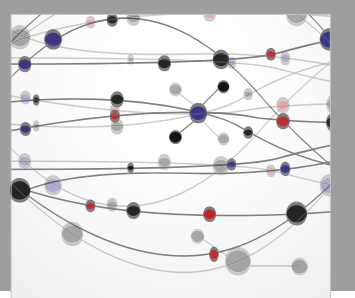

The Scientific World Journal
Submit your manuscripts at

Computing
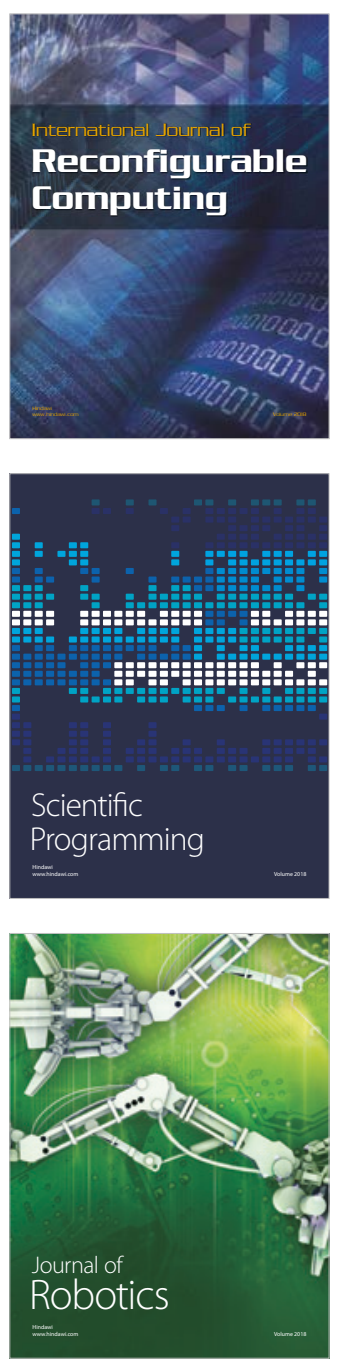

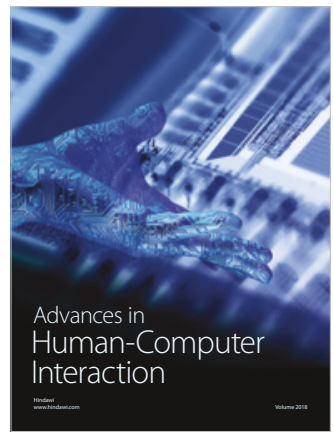

Human-Compute

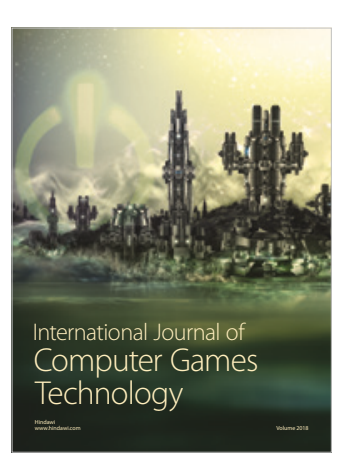

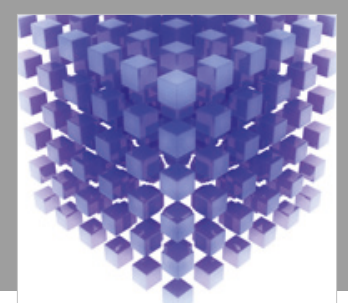

Mathematical Problems in Engineering

\section{Engincering}
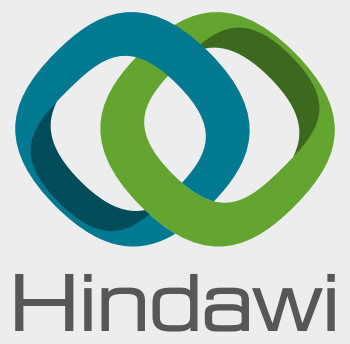

www.hindawi.com
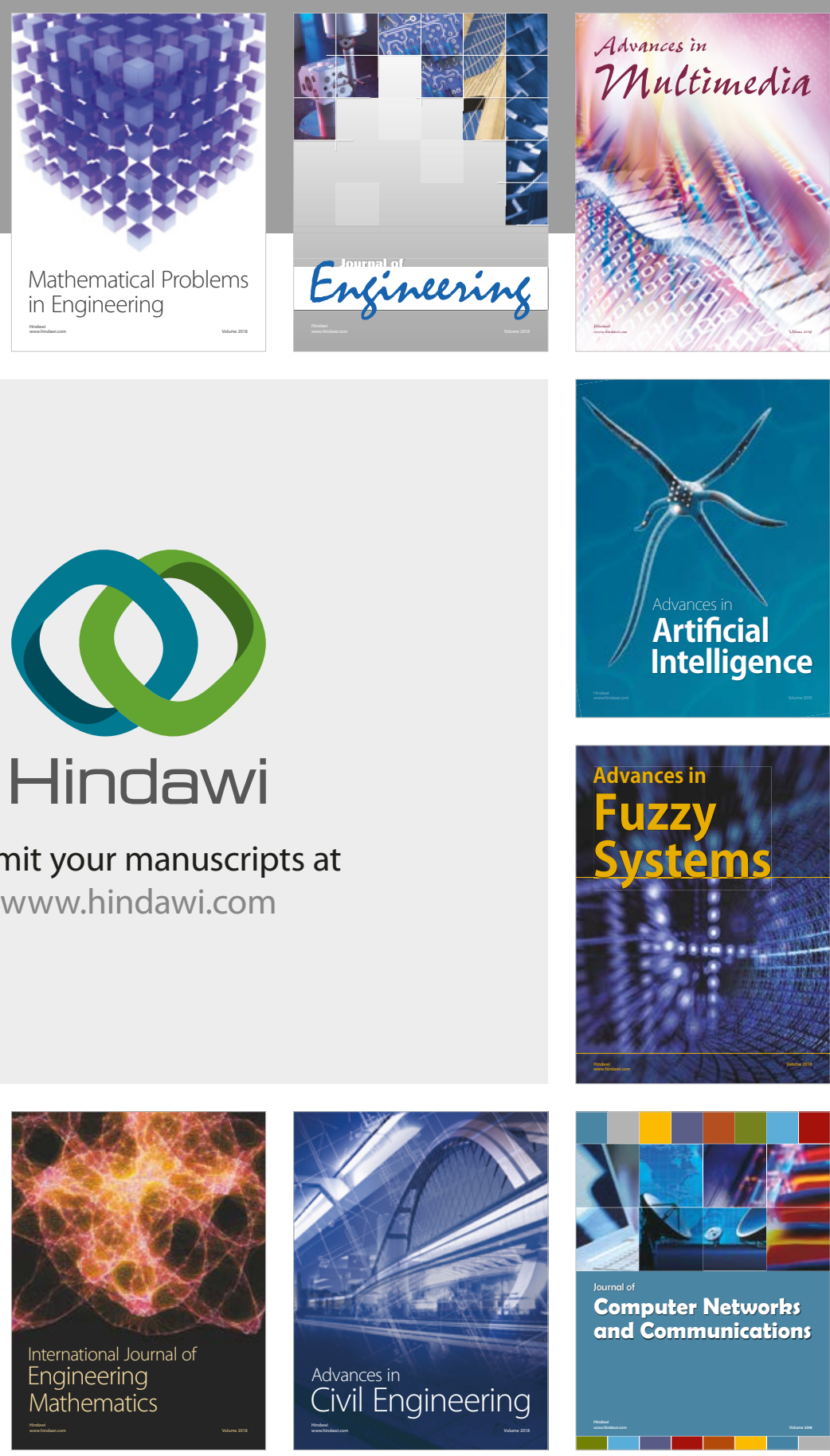

Computer Networks and Communications

Multimedia
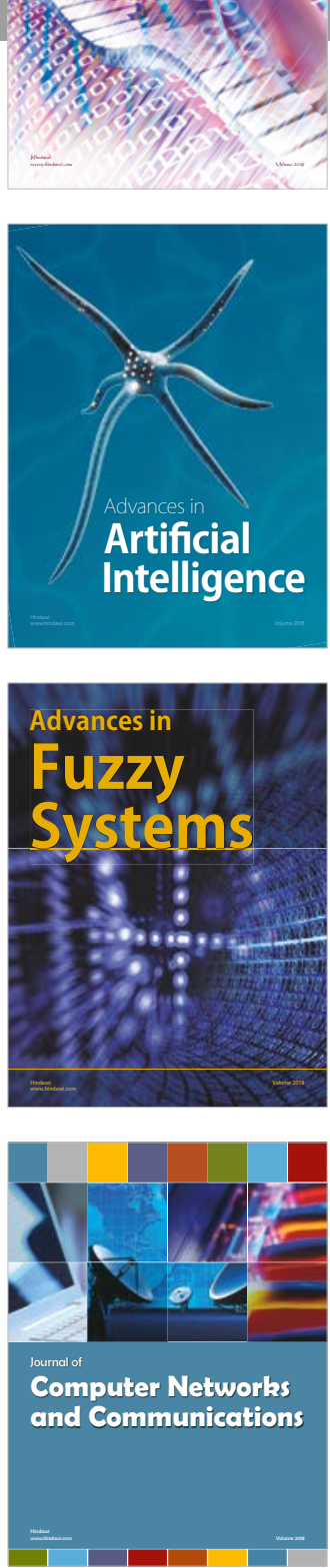

Advances in

Modelling \&

Simulation

in Engineering

interaction

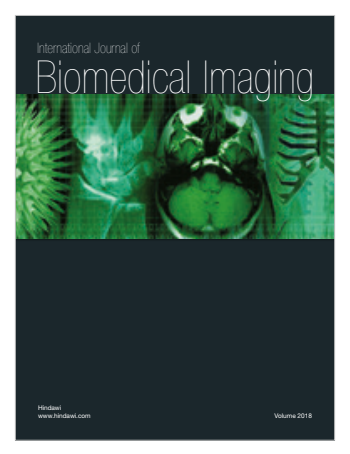

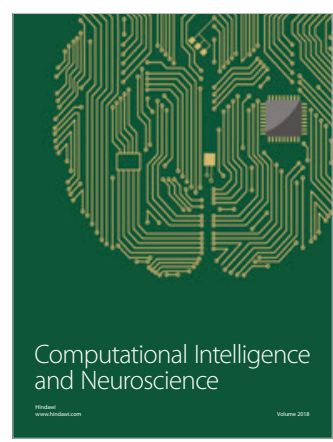

